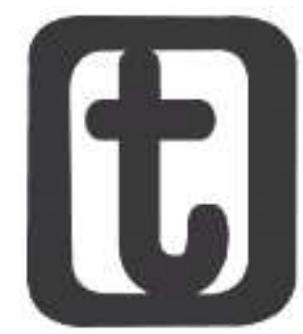

\title{
POLÍTICA DE ASSISTÊNCIA SOCIAL NO BRASIL: UM BALANÇO DA MODERNIZAÇÃO DA GESTÃO
}

\author{
Social assistance policy in Brazil: a balance sheet of modernizing management
}

\author{
Mossicleia Mendes Silva* \\ http://orcid.org/0000-0002-1943-4795
}

\section{RESUMO}

O presente trabalho objetiva discutir o processo de modernização da gestão da política de assistência social no Brasil, nos governos petistas, refletindo sobre os mecanismos conservadores que atravessam o processo de constituição dos marcos normativos da referida política social. Não se desconsidera a importância da normatização e institucionalização de que foi objeto no período em questão, mas visa problematizar os limites e desafios que se reproduziram. Neste sentido, discutimos os processos pelos quais tais movimentos impactam na intensificação do gerencialismo produtivista sobre o trabalho dos profissionais que atuam no Sistema Único de Assistência Social (SUAS). Quanto aos procedimentos metodológicos, cabe explicitar tratar-se de um estudo qualitativo, com duas dinâmicas investigativas associadas: revisão teóricobibliográfica e análise documental com fontes primárias e secundárias.

\section{PALAVRAS-CHAVE}

Assistência Social. Modernização. Produtivismo.

\begin{abstract}
The present work aims to discuss the process of modernizing the management of social assistance policy in Brazil, in PT governments, reflecting on the conservative mechanisms that go through the process of constituting the normative frameworks of that social policy. The importance of the standardization and institutionalization of which it was object in the period in question is not disregarded, but aims to problematize the limits and challenges that have been reproduced. In this sense, we discuss the processes by which such movements impact the intensification of productivist managerialism on the work of professionals working in the Unified Social Assistance System (SUAS). As for the methodological procedures, it is worth mentioning that this is a qualitative study, with two associated investigative dynamics: theoreticalbibliographic review and document analysis with primary and secondary sources.
\end{abstract}

KEYWORDS: Social assistance. Modernization. Productivism.

\footnotetext{
* Assistente Social. Doutora em Serviço Social. Professora Adjunta na Escola de Serviço Social da Universidade Federal do Rio de Janeiro, lotada no Departamento de Política Social e Serviço Social aplicado. (UFRJ, Rio de Janeiro, Brasil). Av. Pasteur, 250/ Fundos, Urca, Rio de Janeiro (RJ), CEP.: 22290-240. E-mail: mossi_c@yahoo.com.br.
}

DOI 10.22422/temporalis.2020v20n39p84-101 material em qualquer suporte ou formato, bem como adaptar, transformar e criar a partir deste material para qualquer fim, mesmo que comercial. O licenciante não pode revogar estes direitos desde que você respeite os termos da licença.

Temporalis, Brasília (DF), ano 20, n. 39, p. 11-26, jan./jun. 2020. | ISSN 2238-1856 


\section{tempordilis}

\section{INTRODUÇÃO}

$\mathrm{N}$ ão é precisamente uma novidade afirmar que marcas conservadoras abalizam a construção sociohistórica da política de assistência social, no Brasil. Tampouco é algo novo demonstrar que a lógica do conservadorismo atravessa a formação social brasileira e se reproduz na esfera da reprodução, como no campo da assistência social. Nosso objetivo é traçar elementos de análise para pensar a permanência e constituição de novos mecanismos conservadores que atravessam o processo de constituição dos marcos normativos da política social, consolidados a partir de 2004, problematizando os mecanismos pelos quais a modernização da gestão impactam na realização dos serviços socioassistenciais na medida em que mecanizam e burocratizam o trabalho dos diversos trabalhadores que atuam no processo de trabalho no âmbito do SUAS.

Neste sentido, apresentamos pontos de reflexão sobre a modernização da gestão da política de assistência social, apontando as ações desenvolvidas a partir do Plano Brasil sem miséria (BRASIL, 2011) e os diversos mecanismos de produção de informações e avaliação. Na sequência, faremos ilações acerca desse movimento, demonstrando alguns elementos que apontam para o aprofundamento do tecnicismo produtivista, que advém dessa modernização da gestão, impactando no trabalho profissional dos trabalhadores do SUAS.

Quanto aos procedimentos metodológicos, cabe explicitar tratar-se de um estudo qualitativo, com duas dinâmicas investigativas associadas: revisão teórico-bibliográfica e análise documental, com fontes primárias e secundárias.

\section{MODERNIZAÇÃO DA GESTÃO DA POLÍTICA DE ASSISTÊNCIA SOCIAL: REFERÊNCIAS ÍDEO- TEÓRICAS}

Ainda que em um contexto de regressão das políticas sociais, a aprovação da PNAS, em 2004, foi um marco importante para regulamentação de política de assistência social. Pereira (2007) esclarece que a PNAS aprovada em 2004 apresenta diferenças importantes em relação à PNAS de 1998 e por este motivo demandava também a aprovação de uma nova NOB, em substituição às NOBs de 1997 e 1998. Estes novos documentos, portanto, condensam novidades: definição da assistência social como política de proteção social; delimitação das proteções que ela deve assegurar; territorialização da ação; instituição do Sistema Único de Assistência Social (SUAS).

A nova PNAS traz, portanto, parâmetros importantes para a implementação do SUAS, demarcando uma mudança substancial, ao menos em termos de normatização, das questões definidas na Lei Orgânica de Assistência Social (LOAS) e das próprias demandas de setores ligados à assistência social que há tempos pleiteavam por uma direção normativa da política.

É sob os impulsos das designações da PNAS e da nova correlação de forças políticas nos aparelhos do Estado que se aprova, em 2005, a Norma Operacional Básica do Sistema 
Único de Assistência Social (NOB-SUAS)' que representou a tentativa mais sistematizada de materialização da LOAS (BRASIL, 2004) e viabilizou a constituição de um sistema com comando único, participativo e descentralizado, com mecanismos de gestão bem delimitados e importantes passos na consolidação de uma cultura de controle social, com a instituição dos Conselhos deliberativos e a realização de Conferências nas diversas instâncias administrativas.

O "[...] choque de gestão na política de assistência social [...]” (BEHRING, 2009, p.86). consolidou um movimento importante de institucionalização, normatização e regulamentação dos programas, projetos, benefícios, serviços e projetos sobre um sistema único descentralizado e participativo de fundamental importância, no âmbito de uma política social marcada pelo histórico descaso, casuísmo, fragmentação e confusionismo entre o público e o privado, com forte presença do caldo cultural conservador do assistencialismo, do paternalismo e da benemerência.

A partir de então, se processou, no âmbito da política de assistência social, um amplo processo de regulamentação que é marcado pela modernização técnica e teórico-jurídica do aparato institucional e do sistema de informações, assim como os mecanismos de gestão com a correlata ampliação dos equipamentos sociais.

Essa expansão, na primeira década dos anos 2000, é marcada pela centralidade dos programas compensatórios de transferência de renda, que já vinha sendo gestada desde os anos 1990 no âmbito das reformas estruturais desembocadas sob o manto do neoliberalismo. Uma das injunções dessa opção de política social é a prevalência do corte seletivo e focalista, que consolida um modo particular de lidar com a pobreza, que se reduze a gerir as suas expressões mais drásticas. Assim, aludimos que este é dos ranços conservadores que atravessam, historicamente, a política de assistência social brasileira.

No cerne do âmbito teórico-normativo, para além da assimilação, na estruturação da PNAS e do SUAS dos parâmetros teóricos do Sistema Único de Saúde (SUS), ${ }^{2}$ podemos elucidar as origens mais profundas de influências que sedimentam aportes teóricos conservadores, as quais se encontram ancoradas nas produções teóricas de Ulrik Beck (teoria do risco), Robert Castel (vulnerabilidade e exclusão), Amartya Sen (potencialidades) (OLIVEIRA, 2014).

\footnotetext{
${ }^{1}$ Não é possível esquecer que o SUAS acompanha parâmetros organizativos do SUS, no sentido de ser uma estratégia de gestão da política em que são estabelecidas formas de acesso, serviços e complexidades, cooperação entre entes públicos e privados, entre outras normativas.

${ }^{2}$ Pereira (2007) traz alguns pontos importantes. A autora atesta que, ao tentar reproduzir o SUS, o Sistema Único da Assistência Social tomou como parâmetro um instrumento que não teve como referência as particularidades relativas ao campo da política de assistência social, impondo sérias complicações ao SUAS. "Como uma política setorial e universal como a da saúde, que obedece a protocolos internacionais gerais, poderá servir de espelho fiel para uma política intersetorial e particularista como a de Assistência, que não possui protocolos internacionais e cujos avanços teóricos, democráticos e cívicos restringem-se particularmente ao Brasil? Como justificar, na Assistência, a incorporação de um sistema que, na Saúde, emprega termos ou conceitos especializados, cuja conotação difere ou se antagoniza com o sentido dos mesmos no âmbito da Assistência, a saber: na Saúde, a assistência não é uma ação promotora, mas cuidadora ou reparadora; na Saúde, o que promove é a atenção, e não a assistência; e, na Saúde, o termo coletivo é muito mais consistente e valorizado do que o termo público que, na Assistência, é mais do que coletivo: é sinônimo de universalização" (PEREIRA, 2007, p. 78-79, grifos da autora).
}

Temporalis, Brasília (DF), ano 20, n. 39, p. 11-26, jan./jun. 2020. | ISSN 2238-1856 
Conforme atesta Alvarenga (2012), estes conceitos foram assimilados e tornaram-se orientadores da PNAS de modo não homogêneo ou consensual, o que demonstra a existência de projetos diferenciados e em disputa pela direção sociopolítica da assistência social pública, no Brasil. Ademais, a entronização dessas influências ídeo-teóricas no campo normativo da política de assistência social não obedeceu a uma leitura profunda e consistente dos autores que teorizam acerca desses conceitos. Segundo a autora, de fato, a incorporação desses conceitos se deu muito em função de estarem em voga em outras políticas sociais como a saúde, a educação, os direitos da criança e do adolescente.

Assim, é importante frisar que quando afirmamos a influência desses autores na formulação da PNAS não estamos dizendo que houve estudos sistemáticos, pesquisas bibliográficas para fundamentar a PNAS. Na verdade, nem mesmo há no texto da PNAS uma explicitação clara e consistente destes conceitos que permita balizar concretamente essa fundamentação.

$\mathrm{Na}$ verdade, trata-se de um processo mais amplo e complexo que diz respeito à própria constituição de uma "nova pedagogia da hegemonia", como demarcou Neves (2005), ao discutir sobre as teorias que passam a embasar as produções/ações das organizações do capital e seus intelectuais orgânicos, no cerne da luta pela construção do consenso, processo fundamental à hegemonia burguesa no quadro da crise do capital.

Trata-se da atuação incisiva e da influência das agências multilaterais na difusão de ideias, valores, conceitos, nomenclaturas, estratégias, enfim, uma nova narrativa, que apesar de apresentar novos termos, condensa um conteúdo conservador que converge para declarar falidas as explicações críticas das relações sociais, cuja centro de análise são as relações entre as classes fundamentais do capitalismo, fundando-se na perspectiva da chamada "terceira via".

É neste terreno, que nos anos 2000 os organismos internacionais e/ou agências multilaterais passam a dar ênfase também à "teoria do risco social”, que tanto quanto à perspectiva da "terceira via" reproduz a "[...] visão conservadora, a ideia de naturalização da forma de organização social corrente e a noção de triunfo do capitalismo" (NEVES, 2005, p. 42).

Em seu estudo, que contou com diversas entrevistas com os principais sujeitos governamentais, militantes e teóricos que participaram diretamente da produção da PNAS, Alvarenga (2012) traz alguns elementos e falas que lançam luz sobre esse processo.

\footnotetext{
Sposati explicitou que, entre os termos discutidos, risco e vulnerabilidade foram escolhidos como orientadores das ações da assistência social. Todavia não consta na Ata explicações mais aprofundadas sobre a inscrição destes termos no texto da PNAS. De todo modo, fica claro nas falas de Aldaíza Sposati e Dirce Koga que riso e vulnerabilidade fazem parte da nova concepção da política proposta, são relevantes para identificar as demandas, os usuários e, consequentemente, para conduzir as ações a serem assumidas pela assistência social. Embora algumas pessoas tenham levantado a necessidade de discutir as concepções das expressões presentes na PNAS, e que o próprio MDS tenha colocado risco e vulnerabilidade como desafios conceituais, debater os conceitos nos encontros do CNAS não fazia parte dos objetivos (ALVARENGA, 2012, p. 104).
} 
A existência de divergências entre os próprios colaboradores ${ }^{3}$ do Ministério, quanto ao significado dos termos, culminou na opção em não explicitar a concepção atribuída aos mesmos. Ao tematizar quanto à forma como estes termos foram parar no texto da PNAS, Alvarenga (2012) aponta que os entrevistados indicam as experiências municipais dos serviços de assistência social, como São Paulo e, enfaticamente, a atuação de Aldaiza Sposati ao trazer os termos na discussão da PNAS e as compilações da política de saúde, em que já vigoravam concretamente tais termos. A pesquisa indica ainda a influência do Banco Mundial, o pensamento francês, com destaque para Durkhein e a ideia de coesão social. Mas, como sinalizamos, essa apropriação não se deu sistemática e propositalmente, como informa uma das entrevistadas do estudo de Alvarenga (2012).

\begin{abstract}
Maria Luiza Rizzote acredita que se houve mesmo a apropriação de alguns autores europeus e também de Armatyan Sen, ela não aconteceu propositalmente. Mas a influência seria justificável, visto que esses autores são os que respondem às necessidades que aparecem no cotidiano. Falar em perdas reais atreladas as expressões da questão social é mais visível do que tratar de seu cerne - a exploração do capital sobre o trabalho -, então esses autores europeus acabam tendo mais visibilidade no campo da assistência social do que o próprio Marx (ALVARENGA, 2012, p. 110).
\end{abstract}

Essa discussão se insere na nossa argumentação como sendo parte do que denominamos de modernização conservadora na medida em que tais teorias, termos e conceitos oferecem um arsenal sofisticado de um novo viés político-teórico, assentados na perspectiva da "terceira via", da teoria dos riscos", cuja narrativa central visa fornecer um novo léxico semântico e conceitual às novas questões postas pela chamada "modernidade reflexiva", ou "sociedade pós-tradicional". No campo da assistência social termos considerados antiquados, obsoletos e pejorativos como carência, necessitados, desamparados são substituídos por termos e noções que são considerados mais apropriados à nova conjuntura da sociedade, em que os antigos problemas relacionados às relações de classe, às demandas do trabalho industrial assalariado estariam supostamente superados, requisitando novas formas de abordagem, como a própria noção de "risco e vulnerabilidade”, “empoderamento”, “desenvolvimento com capacidades”, “território”, entre outros.

Mais uma vez, vale retificar o significado histórico, tanto nos aspectos políticos, culturais, sociais e, sobretudo, jurídicos, que o "choque de gestão" da política de assistência social tem no contexto de um país com a formação social do Brasil, cuja lógica do favor e do nãodireito perpassam perenemente as políticas sociais. Evidentemente, a contradição é elemento intrínseco à política social, e, desse modo, a política de assistência social condensa um feixe dessas contradições que se dão igualmente no âmbito da disputa política em torno da direção social que assume. Foi este campo de disputas que possibilitou todo acúmulo histórico que permite dotar a assistência social de uma institucionalidade no campo dos direitos sociais, que, inclusive, expressa uma forma de resistência face ao duríssimo ataque conservador neoliberal, ainda que, muitas vezes, sob os desígnios do chamado "social-liberalismo".

\footnotetext{
3 Trata-se de intelectuais e técnicos requisitados pelo MDS para assessorar e auxiliar no processo de construção da PNAS, como a própria Aldaiza Sposati, Maria Luíza Rizzote, Dirce Koga, Simone Albuquerque, Márcia Lopes, Berenice Rojas Couto, Maria Carmelita Yazbek, entre outros.
}

Temporalis, Brasília (DF), ano 20, n. 39, p. 11-26, jan./jun. 2020. | ISSN 2238-1856 
Neste sentido, a disputa pela direção sociopolítica no campo da assistência social é um permanente campo de conflito em que perspectivas neoconservadoras e vias mais progressistas constituem um espaço permanentemente aberto para construção de alternativas populares, em defesa de uma política de assistência social verdadeiramente assentada em valores de universalização de direitos, ampliação e qualificação dos serviços e benefícios, tendo como fundamento central as reais demandas dos usuários.

O modo pelo qual o SUAS é implementado é carregado de uma série de contrassensos e até mesmo inconsistências que dificultam substancialmente a consolidação do padrão de proteção social assegurado na Constituição Federal e a solidificação de uma rede de serviços sociassistenciais de fato pública e de qualidade. ${ }^{4}$ Infelizmente, esse processo de regulamentação da política e implementação do SUAS, apesar do valor simbólico e material que comporta para assistência social, se processa em um contexto onde a crise do capital e sua ofensiva conservadora abalizam novos determinantes ao processo que convergem na direção dos próprios interesses dominantes, na medida em que se realizam mediante forte influência de uma segunda geração de ajustes neoliberais (SILVA, 2018).

A assistência social, neste contexto, ganha uma magnitude antes impensável. Do ponto de vista da narrativa oficial, a política tem papel fundamental no "alívio à pobreza" e no combate à "vulnerabilidade social". Expande-se, assim, centrando sua intervenção sobre os mais pobres, com proeminência dos programas de transferência de renda. Do ponto de vista da análise marxista que realizamos, o que se processa é uma verdadeira investida político-ideológica e prático-concreta no sentido de conferir à assistência social capacidade operacional e administradora para incidir sobre a classe trabalhadora, sobretudo, administrar emergencialmente as condições de vida da superpopulação relativa, ao mesmo tempo, em que atende necessidades objetivas e se torna o único recurso legal e público de reprodução para a classe trabalhadora desprovida de trabalho e direitos.

Isto se dá em meio a um processo que galvaniza um arsenal heurístico totalmente reconceituado, cuja influência das novas teorias difundidas pelos organismos internacionais, parece decisiva. Entre outros elementos, tais teorias e instituições propalam a defesa de um novo padrão de proteção social, que zela por desmantelar a estrutura de seguridade social erigida a partir dos ganhos do trabalho, advindos de duras lutas políticas, que encerram formas de proteção pautadas na universalidade, no dever do Estado e na própria solidariedade intergeracional dos trabalhadores, como no caso da previdência social pública.

\footnotetext{
4 É claro que, mesmo que fosse assegurado o preceito constitucional e a política de assistência social assumisse a direção de uma política de proteção social de caráter universalizante e que o SUAS tivesse um alto padrão institucional e profissional, não seriam suplantadas as contradições da política social, já que estas são inerentes à sua lógica no âmbito do capitalismo. O processo de recomposição do valor sempre recompõe o pressuposto básico do modo de produção capitalista: ter força de trabalho disponível para as necessidades imediatas de produção, uma vez que é apenas pela exploração do trabalho vivo que se obtém valor e maisvalor. Assim, o processo de produção e reprodução das relações sociais capitalistas recompõe sempre, na medida da acumulação, a ampliação do proletariado. Deste modo, quanto mais riqueza é produzida, pela exploração da classe trabalhadora, mais pobreza é gerada, conforme demonstrado por Marx ao explicitar a lei geral de acumulação capitalista, discutida no primeiro capítulo desta Tese. Logo, mantidas as relações capitalistas, é impossível erradicar a pobreza. Portanto, nenhuma modalidade de política social pode suprimila, como menciona a narrativa governamental sobre a erradicação da pobreza.
}

Temporalis, Brasília (DF), ano 20, n. 39, p. 11-26, jan./jun. 2020. | ISSN 2238-1856 


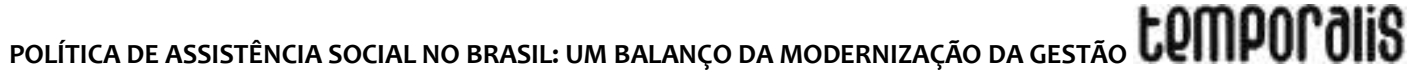

\section{O PLANO BRASIL SEM MISÉRIA: MODERNIZAÇÃO DA GESTÃO E PRODUTIVISMO}

O paradigma da focalização passa, nos governos do Partido dos Trabalhadores (PT), a ter centralidade no discurso sobre a garantia do acesso da população mais pobre aos serviços públicos. No primeiro governo de Dilma Rousseff a implementação do Plano Brasil sem miséria (PBSM), a partir de junho de 2011, explicita o aprofundamento dessa dimensão, associada a um intenso processo de sofisticação e modernização do aparato institucional para gestão da pobreza.

Neste processo, o PBSM se configura como resposta governamental às fragilidades identificadas no Programa Bolsa Família (PBF), principalmente no que diz respeito ao acesso aos serviços essenciais e a superação da extrema pobreza no país, ao mesmo tempo em que consolida o padrão de "enfrentamento à pobreza" que já se constituía nos anos anteriores.

A narrativa dos governos do PT apresentava a perspectiva de modernizar a gestão da política de assistência social como orientação para construção da rede de serviços do SUAS e, por isso, teria sido objeto de avaliações e reformulações dentro do esforço de superar as dificuldades e desafios postos ao processo. A constituição de um sistema de avaliação e monitoramento responde, contraditoriamente, a demandas de enfrentamentos de desafios para o avanço progressista da política, o que é absolutamente legítimo, como assume, também, uma direção que prima pela melhoria em indicadores meramente quantitativos.

No cerne deste movimento contraditório, o Censo SUAS é um mecanismo acionado para acompanhar o desenvolvimento dos equipamentos sociais, que tanto pode servir ao desenvolvimento de melhorias nos serviços e benefícios, como também parametra uma lógica produtivista/quantitativa que se centra no auferimento de resultados para garantia de repasses de recursos federais, como é o caso do IGD-SUAS.

A forma de co-financiamento, que organiza o formato de divisão de responsabilidades orçamentárias entre diferentes instâncias político-administrativas, principalmente entre União e municípios, é um avanço em termos de garantia de repasses de recursos do âmbito federal para o municipal. Os aspectos produtivistas, que assentam as bases para calcular o valor dos repasses é que nos parece problemática, por que engessa sobremaneira a rotina e cotidiano de trabalho dos profissionais que atuam nos serviços socioassistenciais para dá conta de contabilizar e inserir no sistema dados que visam quantificar os atendimentos para determinar os valores de recursos a serem recebidos do governo federal.

De acordo com informações do Comitê de Estatísticas Sociais do INSTITUTO BRASILEIRO DE GEOGRAFIA E ESTATíTICA (IBGE), o processo de monitoramento da política de assistência social começa em 2007, com a implantação do CENSO/CRAS através da Ficha de monitoramento. Em 2018 "[...] foi implantado o questionário eletrônico, cujas informações declaradas pelos agentes municipais e do DF possuem fé pública e constituem registros administrativos do sistema de informação do SUAS" (INSTITUTO BRASILEIRO DE GEOGRAFIA E ESTATÍTICA, 2014, não paginado). Os CREASs tiveram seu questionário implantado em 2009, e em 2011 foi ampliado o inquérito para os Conselhos estaduais e municipais, Gestores municipais e Estaduais, a Rede Privada e Centros de Referência 
Especializados para pessoas em situação de rua. Os últimos a incorporarem o inquérito foram as Unidades de Acolhimento em detrimento da Rede Privada, já em 2012.

No contexto do que estamos denominando de modernização da gestão da política de assistência social, a produção e o monitoramento de informações tem sido estratégia central dos governos para o campo da política de assistência social. De acordo com o Ministério do Desenvolvimento Social e combate à fome (MDS), a SAGI “ [...]é a unidade [desse Ministério] responsável pelas ações de gestão da informação, monitoramento, avaliação e capacitação de agentes sociais" (BRASIL, 2010, não paginado). . A SAGI atua em diferentes frentes, mas que se articulam entre si: produção de pesquisa para análise de impacto dos programas sociais; elaboração de indicadores que auxiliam no acompanhamento de programas e ações do MDS; e combinando estas duas frentes, compõem a terceira que é o auxílio aos gestores na gestão dos diversos segmentos que compõem o MDS.

Todo esse arsenal técnico condensa mecanismos de gerencialismo que se adensa na assistência social nos governos do PT, não desconsiderando a reforma gerencialista do Estado, sob o governo de Fernando Henrique Cardoso, que deixou marcas importantes no Estado e na política social brasileira. Esse processo se fundamentou em mecanismos de produtivismo, pautado em mudanças técnicas e procedimentais que visam o alcance ótimo de objetivos quantitativos, com relação à cobertura e eficiência do sistema, procurando dotar a esfera da ação pública do padrão organizativo da empresa privada (BEHRING, 2008). Isso de fato imprime novos contornos à política, e, em que pese o fato de ganhos no que diz respeito à profissionalização da política de assistência social, prevalece a orientação da racionalidade instrumental que hipostasia o aparato tecnocrático.

Os sistemas de avaliação, desse modo, consolidados sob o mantra da modernização da gestão, introduziram formas de controle de metas, ações e dados que focalizam os resultados quantitativos. É a lógica instrumental e privatista do mercado que direciona, contraditoriamente, a ação pública, engendrando a racionalidade gerencialista com a maximização do impacto das ações minimalistas do Estado. Tais ações acabam ganhando um arcabouço técnico-administrativo tão robusto que canaliza as ações da política social para manuseio, alimentação e monitoramento destes dados a partir de variáveis empíricasquantitativas bem ao gosto dos vieses neopositivistas enraizados nas estratégias de intervenção na questão social, sobretudo, nas demandas atinentes à pobreza.

Não podemos minimizar a importância de pesquisas, diagnósticos e levantamentos de dados e dos processos avaliativos e de monitoramento, no campo da política social, quando estes subsidiam conhecimento efetivo da realidade onde os serviços socioassitenciais da assistência social vão incidir e quando desvelam as reais demandas coletivas dos usuários. Mas, contraditoriamente, esse modus operandi hipertrofia a focalização para uma ação cada vez mais segmentada e segregada.

A modernização da gestão no campo da assistência social passa por essa nuance da intensificação de produção de software, ferramentas digitais e informacionais, base de dados cadastrais que geram um volume de informações, sobre as quais os sujeitos que as 
fornecem não têm muito controle. ${ }^{5}$ A padronização de necessidades sociais via análise destas informações e a constituição de indicadores que fomentam e aprofundam o padrão focalizado e seletivo tem sido muito eficaz na definição dos rumos da política de assistência social, contribuindo para reforçar uma lógica de intervenção nas expressões mais acirradas da questão social, convergindo num processo cada vez mais ampliado de gestão da pobreza.

O Plano Brasil sem miséria (BRASIL, 2011), desse modo, é apresentado e implementado sob esse prisma da inovação na gestão que pode aperfeiçoar a intervenção do Estado na direção de um suposto "empreendedorismo corporativo do setor público". Neste âmbito teórico, o comportamento gerencial está diretamente relacionado com as possibilidades de inovações positivas para o âmbito da ação do Estado na proposição e coordenação de políticas públicas e sociais.

As implicações disto sobre as complexas mediações que se interpõem a composição do trabalho coletivo no âmbito do PBSM não são desprezíveis. Pelo contrário, a distribuição de cargos, Ministérios e Secretarias a diferentes sujeitos políticos - com vieses e filiações partidárias as mais variadas - reverberam sobre a dinâmica do Plano de modo significativo. Os interesses partidários, as demandas enquanto pastas orçamentárias, as institucionalidades e prioridades de cada um dos representantes políticos das diversas esferas envolvidas na efetivação do Brasil sem miséria demandam um intenso esforço de articulação e negociação política. As acomodações feitas, os acordos, os acertos, as combinações compõem as muitas nuances contraditórias da dinâmica de classes infundidas no Estado mediante as representações partidárias que o fetiche da gestão esconde.

Neste particular, a política de assistência social passa por um processo intensivo de modernização institucional do seu sistema de informações, recebe investimentos tanto de reformatação da gestão da política, quanto na ampliação dos equipamentos sociais, sendo capitalizada para os objetivos do PBSM. Em outros termos, com o Plano, o SUAS recebe um "rompante gerencialista" sob o governo petista, acirrando os atributos tecnicistas para resolução das inconveniências da divisão do trabalho na esfera da reprodução das relações sociais, sob a particularidade da atividade pública (SILVA, 2018).

O Plano foi grandioso dentro do limitado domínio da razão político-instrumental. É imponente dentro do formato técnico em que se insere, a partir da lógica instrumental que parametra a ação pública sob a via gerencial. Mas, irremediavelmente contraditório e irracional - do ponto de vista de uma compreensão dialética e emancipatória da razão por que visa enfrentar a outra face inexorável do desenvolvimento capitalista que é a pobreza e ainda por cima, procura fazê-lo tentando controlar, remediar ou até mesmo suplantar os efeitos deletérios da divisão sociotecnica do trabalho no campo da política social. Toda essa artimanha, sob a camuflagem do fetiche da gestão.

\footnotetext{
5 Em maio de 2017 o Ministério do Desenvolvimento Social e Agrário (MDSA) lançou o Consulta Cidadão (BRASIL, [2019]), ferramenta pela qual o governo Temer afirma ter o objetivo de facilitar o acesso do cidadão aos dados do Cadastro Único para Programas Sociais do governo federal e está disponível no site do órgão. Em função das mudanças político-governamentais e as respectivas reordenações institucionais e nos Sites Oficiais, esta página agora é denominada Meu Cadúnico, no qual é possível verificar os mesmos dados do Consulta Cidadão.
} 
O que ocorre com a política de assistência social, seja mediante tentativas de convertê-la em força estatal de "combate à pobreza" ou carreá-la para objetivos paralelos como de programas esporádicos de natureza assistencial, temporária e focalista para aquele mesmo objetivo, é reduzi-la à gestão da pobreza, sob auspícios de mecanismos modernizados e mais eficientes de "trato dos pobres", reforçando a lógica conservadora de que é caudatária. Neste particular, sua atuação fica muito limitada à elegibilidade dos "pobres", que podem vir a ser beneficiados com determinados programas, assegurando que aqueles estratos mais aviltados pelos processos de crise estrutural do capital sejam alcançados.

Para isso, mobiliza-se para o campo da assistência social: recursos para transferência de renda, técnicas aprimoradas para cadastrar indivíduos e garantir o acesso aos serviços a estes mesmos seguimentos, trabalhar com indicadores, monitoramento e "vigilância", de modo a sistematizar a intensificação de ações em situações de maior "vulnerabilidade e "risco", dominar esse arsenal teórico-conceitual e alimentar um sistema de informações sofisticado; dominar competências e habilidades para gestão desse sistema.

A implementação da estratégia também deve está relacionada ao incentivo financeiro que os municípios passaram a receber através do IGD-PBF, com aumento no valor de referência do cálculo do referido índice, que passou a considerar as famílias inscritas no Cadastro Único e não as famílias beneficiárias do Programa. Entre os melhoramentos no Cadastro Único e as medidas para a efetivação da estratégia de busca ativa, o PBSM investiu mais de R\$ 44 milhões (SILVA, 2018). Estabelece-se assim, uma relação técnica-financeira entre os dois mecanismos - busca ativa e cadastramento de famílias - que coloca a assistência social no espectro do produtivismo e do alcance de metas quantitativas.

Os sistemas de gestão e monitoramento de dados modernizados sob os investimentos do PBSM capitalizam a proximidade do SUAS com os estratos mais empobrecidos da classe trabalhadora para fomentar meios genéricos de gerenciamento da pobreza. Não se pode esperar do Estado capitalista que ele atue sobre a raiz da pobreza, por que isso seria o mesmo que enfrentar a própria ordem capitalista. Mas a forma particular como o Estado atua sobre as necessidades da classe trabalhadora evidentemente diz muito sobre o fato de sua direção estar em disputa com possibilidades reais para o tensionamento do trabalho.

A VII Conferência Nacional de Assistência Social é realizada em 2011 na antessala da constituição do PBSM e da iniciação de sua implementação. Nesta Conferência o tema central era a Gestão do trabalho no âmbito do SUAS, considerado um dos principais gargalos para efetivação de serviços de qualidade e efetivos, bem como para aprofundar o caminho de profissionalização da política de assistência social. As demandas relativas à questão do trabalho são evidentemente legítimas e precisam ser enfrentadas no sentido de superar a intensiva precarização das relações e condições de trabalho no âmbito do SUAS. Mas, a via da gestão do trabalho é também um campo em disputa e perpassa pela própria necessidade de constituição de um determinado padrão de trabalho a ser realizado no serviço público. Visando superar alguns obstáculos ainda tangentes à dinâmica da descentralização político-administrativa e, portanto, ao próprio processo de municipalização da política de assistência social, uma dada direção hegemônica para o campo da gestão do trabalho acomoda-se a própria dinâmica de modernização do SUAS, 
com a investida do PBSM. Ou seja, a própria organização do trabalho no âmbito da política passa a ser objeto de uma intensiva via de gestão.

Quando se pensa na estruturação dos serviços do SUAS e da própria "política de recursos humanos" fica patente a questão da divisão do trabalho, dado os aspectos relativos: as diversas profissões que compõem as equipes técnicas, a padronização dos serviços, a divisão entre modalidade de proteções: básica e especial e as formas que assumem mediante a formatação de esquemas tecnocráticos que vão desde a designação de coordenações setoriais, que sempre se dão em cunho de indicação das administrações públicas e não em função de formação profissional, os aspectos de hierarquias e a cisão profunda entre núcleos de elaboração e núcleos de execução dos serviços. Ademais, toda formatação dos programas contam com uma logística pré-definida e moldada sobre a própria demanda técnica a que se submete.

Os diversos mecanismos acionados pela modernização da gestão perfazem o perfil de uma ótica de hipertrofia do gerencialismo em função dos diversos fazeres técnicos préestabelecidos como alimentação de sistemas, rotinas institucionais, formulários, coleta de dados, busca ativa, acompanhamento de condicionalidades, termos de adesão. Tarefas estas altamente parceladas, cindidas entre gestão da política e execução dos serviços, que ao final complexificam a divisão do trabalho, ao tempo que oferecem a própria condição elementar dessa mesma divisão do trabalho: a perda de controle dos trabalhadores - no caso dos técnicos que operam os serviços - sobre o processo total do trabalho e do resultado final dele.

É evidente que este processo não passa sem conflito, haja vista a relação da autonomia profissional com o controle técnico a que estão submetidos. Por certo, isto impacta na disputa pela direção da política de assistência social, pois o próprio movimento de profissionalização da política de assistência social contribui para construção de uma cultura profissional de defesa da ampliação de fundamentos e práticas progressistas para o SUAS e disputa a reprodução de práticas profissionais alterativas à lógica meramente burocrática e produtivista. No entanto, tal movimento encontra imensa dificuldade de se aprofundar meio aos processos de precarização do trabalho e flexibilização das relações trabalhistas que vem na esteira da ofensiva esmagadora para imputar uma dada lógica tecnicista e instrumental à política social, em que a própria luta pela direção social de cada parcela social do trabalho coletivo torna-se pouco impactante em função da perda de controle do processo total. ${ }^{6}$

O fetiche da gestão também comparece neste aspecto concorrendo para a transformação de trabalhadores - com saberes teóricos, práticos e valores éticos próprios e concernentes a suas diferentes formações profissionais - em instrumentos a serem gerenciados com vistas à produtividade e consequente alcance de dados objetivos e metas específicos.

\footnotetext{
${ }^{6}$ De modo algum essa preposição pressupõe a impossibilidade da ação transformadora dos sujeitos. Apenas chamamos atenção para o fato de que as disputas políticas em torno da direção da política de assistência social, apesar de gerar contradições e espaços de ganhos também para o campo progressista, vem sofrendo reveses impostos pelo campo conservador, instrumental e gerencialista/produtivista.
}

Temporalis, Brasília (DF), ano 20, n. 39, p. 11-26, jan./jun. 2020. | ISSN 2238-1856 


\section{CONSIDERAÇÕES FINAIS}

As breves reflexões aqui expostas indicam para a consolidação de um movimento denso e contraditório que marca as transformações no campo da política de assistência social durante os governos do PT. Isto por que, no período analisado houve importantes ganhos no campo da normatização, expansão de equipamentos e serviços, instituição de uma cultura de direitos e controle social, mas, por outro lado, o processo de modernização da gestão incorporou uma espécie de reificação dessa gestão, como se ela tivesse incorporado as próprias características humanas e fosse dotada de vida própria, portando a capacidade de dirimir os efeitos da própria divisão do trabalho e fragmentação das necessidades sociais.

E, além disso, impetrou aos trabalhadores que a executam formas de submissão - mesmo que parciais - ao seu quadro amplo de técnicas, procedimentos, padrões operativos, sendo capacitadas para reproduzir esse mesmo aparato, numa concepção estritamente tecnicista e instrumental do processo da intervenção humana no campo da ação pública. É evidente que a investida gerencialista e tecnicista não sejam exclusivas à política de assistência social, uma vez que elas operam de um modo mais amplo no próprio processo de recomposição do capital e contrarreforma do Estado. Também é preciso enfatizar que os sujeitos profissionais são dotados de relativa autonomia e também empreendem processos de disputa pela constituição de práticas e saberes alternativos a essa lógica e fundada nas demandas de ampliação dos serviços e necessidades reais dos usuários. $\mathrm{E}$, além disso, os próprios usuários tencionam essas práticas ao endossarem demandas que ultrapassam o limite imediatista da lógica tecnicista.

Toda ação do Estado capitalista é muito mais complexa e contraditória do que sua performance na gestão. É uma tentativa mais ampla de anular o conflito que está na base da direção que o Estado assume no capitalismo e sua real condição classista. Nada mais fecundo à dominação irrestrita do capital do que tentarem ocultar as implicações de classe que estão subjacentes às práticas efetivadas, sob o escrutínio da tal neutralidade que os aprimoramentos técnicos supostamente comportam. Trata-se, ao fim e ao cabo, da fetichização da técnica de gestão.

São muitos os vieses e mediações pelas quais a ideologia hegemônica adentra os mais diversos campos da vida social. Entre a assistência social e o PBSM, o intricado de conexões que viemos problematizando pauta à ofensiva conservadora com verniz moderno, que aprofunda as determinações da fragmentação e parcelamento do trabalho coletivo no âmbito do SUAS, limitando o potencial pedagógico do trabalho profissional nas instituições, impondo formas de restringir sua atuação aos aspectos técnico-burocráticos e produtivistas.

A partir do governo Temer, o PBSM começa a declinar e o referido governo anuncia a criação o Programa Criança Feliz, que vai em direção análoga à via focalista e produtivista do Brasil sem miséria. Embora tenhamos mostrado os limites do processo de modernização da gestão da política em questão, não negamos os avanços alcançados na área, inclusive em termos de legitimidade e institucionalidade, compondo outro lugar na esfera do governo Federal. Tal processo começa a minguar com cortes orçamentários a 
partir de 2017 e se aprofunda em 2018 face à intensificação do ajuste fiscal e da ofensiva ultraconservadora do capital em direção às políticas sociais.

Com a chegada de um governo de extrema direita ao governo federal, o processo de desmonte da já frágil estrutura do SUAS - com a continuidade do corte de recursos - é acompanhada por uma ofensiva político-ideológica contra a institucionalidade democrática construída na área nos últimos anos, do que é elucidativo a desestruturação dos Conselhos de Direitos e a não convocação da Conferência Nacional de Assistência Social, que deveria ter sido realizada em 2019. Além disso, mudanças importantes no âmbito ministerial, com transformação do MDS no Ministério da Cidadania, operado com desmonte de áreas importantes como no campo dos direitos das mulheres, da população LGBQ+, dos grupos étnicos e tradicionais entre outros.

Para completar o rol das investidas conservadoras de forte cariz reacionário, foi lançado, em 2019, o Programa Pátria Voluntária, que tem como presidente a primeira-dama do país, Michele Bolsonaro e se assenta nas chamadas parcerias público-privadas. Em uma única tacada o governo renova práticas que remota à pior cultura histórica do campo da assistência social: o primeiro-damismo e o voluntariado.

Os desafios que se colocam nos dias atuais em torno da defesa dos direitos sociais, dos quais destacamos a assistência social pública, são complexos e demandarão organização política que articule trabalhadores e usuários, pesquisadores e movimentos sociais. As reflexões aqui expostas, sobre os desafios e limites do que denominamos de modernização da política de assistência social - realizada sob os governos petistas - não desmerecem os avanços alcançados no contexto referido. Pelo contrário, apontam para a necessidade permanente de fazer a crítica rigorosa da política social e suas contradições no capitalismo, ao mesmo tempo em que reconhecemos sua necessidade imediata em termos de reprodução material da classe trabalhadora, sob a sociedade regida pelo capital.

Os ataques brutais pelo que passam os direitos dos trabalhadores e trabalhadoras, 0 desmonte da já parca estrutura de proteção social brasileira tão jovem não pode gerar saudosismo das conquistas alcançadas no período anterior. Obrigam-nos, sim, a defendêlas, sem perder de vista seus limites reais, suas contradições fundamentais e a imprescindível necessidade de organização para lutas mais amplas, que extrapolem a posição meramente defensiva e nos encaminhe para disputas mais radicais.

\section{REFERÊNCIAS}

ALVARENGA, M. S. Risco e vulnerabilidade: razões e implicações para o uso na Política Nacional de Assistência Social. 2012. Dissertação (Mestrado em Política Social)- Programa de Pós-Graduação em Política Social, Universidade Federal do Espírito Santo, Vitória, 2012.

BEHRING, E. Notas para um Balanço Crítico do SUAS: a título de Prefácio. Revista Em Foco, Rio de Janeiro: Conselho Federal de Serviço Social, n. 5, 2009.

BEHRING, E. Brasil em contra-reforma: desestruturação do Estado e perda de direitos. 2. ed. São Paulo: Cortez, 2008. 
BRASIL. Decreto n. ${ }^{\circ}$ 7.492, de 2 de junho de 2011. Institui o plano Brasil sem Miséria. Brasília (DF), 2011. Disponível em: http://www.planalto.gov.br/ccivil_03/_Ato20112014/2011/Decreto/D7492.htm. Acesso em: 8 out. 2017.

BRASIL. Lei nº 8.742/93. Lei Orgânica da Assistência Social (LOAS). Brasília (DF), 1993.

BRASIL. Ministério do Desenvolvimento Social e Combate à Fome. Norma Operacional Básica (NOB/SUAS). Brasília (DF), 2005.

BRASIL. Ministério do Desenvolvimento Social e Combate à Fome. Política Nacional de Assistência Social (PNAS). Brasília (DF), 2004.

BRASIL. Ministério do Desenvolvimento Social e Combate à Fome. Institucional - A Secretaria de Avaliação e Gestão da Informação. Brasília (DF), [2010]. Disponível em: https://aplicacoes.mds.gov.br/sagi/portal/index.php?grupo=164. Acesso em: 3 jan. 2018.

BRASIL. Ministério do Desenvolvimento Social e Agrário (MDSA). Consulta Cidadão/Meu CadÚnico. Brasília (DF), [2019]. Disponível em:

https://meucadunico.cidadania.gov.br/meu_cadunico/. Acesso em: 8 jun. 2017.

INSTITUTO BRASILEIRO DE GEOGRAFIA E ESTATÍTICA (IBGE). Censo do Sistema Único da Assistência Social (SUAS). Brasília (DF), 2014. Disponível em: Disponível em https://ces.ibge.gov.br/apresentacao/portarias.html?id=3581. Acesso em: 3 jan. 2018.

NEVES, L. M. W. (Org.). A nova pedagogia da hegemonia: estratégias do capital para educar o consenso. São Paulo: Xamã, 2005.

OLIVEIRA, Karine Noronha de. A vulnerabilidade social como narrativa da proteção social na era do capital financeiro: fundamentos teóricos e históricos da argumentação dos organismos internacionais. 2014. Dissertação (Mestrado em Serviço Social)- Programa de Pós-graduação em Serviço Social da Universidade do Estado do Rio de Janeiro, Rio de Janeiro, 2014.

PEREIRA, P. A. A assistência social prevista na Constituição de 1988 e operacionalizada pela PNAS e pelo SUAS. Ser Social, Brasília (DF), n. 20, 2007.

SILVA, M. M. Desenvolvimento capitalista e assistência social no Brasil: a encruzilhada da modernização com o Plano Brasil sem Miséria, 2011-2016. 2018. Tese (Doutorado em Serviço Social)- Programa de Pós-graduação em Serviço Social /Universidade do Estado do Rio de Janeiro, 2018.

\footnotetext{
Mossicleia Mendes Silva

Professora Adjunta na Escola de Serviço Social da UFRJDoutora em Serviço Social pelo Programa de Pósgraduação em Serviço Social da UERJ (2018); Mestra em Serviço Social pela UERJ (2013); Graduação em Serviço Social pelo Centro Universitário Doutor Leão Sampaio (2010); Pesquisadora do Grupo de Estudos e Pesquisas Marxistas em Política Social (GEMPS/NEPEM/UFRJ). Estudos e pesquisas voltados para o campo da política de assistência social e as particularidades do Estado social no capitalismo dependente brasileiro no trato as demandas da reprodução da força de trabalho; desenvolvimento capitalista e pobreza.
} 